\title{
Assessing Postpartum Depression Symptoms in Teenage Mothers Using Patient Health Questionnaire- 9: A Preliminary Study
}

\author{
Irma Nurbaeti ${ }^{1 *}$ \\ \{irma.nurbaeti@uinjkt.ac.id \} \\ *corresponding author
}

\begin{abstract}
Nursing Study Program, Faculty of Health Sciences, UIN Syarif Hidayatullah Jakarta, Indonesia, Pisangan Ciputat 15419, Indonesia ${ }^{1}$
\end{abstract}

\begin{abstract}
Postpartum depression is the most mood disorder in the first year after-birth. Higher in teenage than adult mothers. The purpose of this study was to assess symptoms of postpartum depression using Patient Health Questionnaire-9. A descriptive study of 203 teenage' mothers located in West Java Province, Indonesia. Instrument of Patient Health Questionnaire-9 Indonesia version using Google form. Descriptive analysis was performed and reliability test by alpha Cronbach $=0.78$. The findings showed that $32 \%$ participants exhibited symptoms of postpartum depression with the most feeling little interest $33.50 \%$, $52.22 \%$ sleeping problem, $56.16 \%$ feeling tired, $37.44 \%$ poor appetite/overeating and 2.95 thought dead/hurting. Patient Health Questionnaire-9 is good to assess symptoms of depression after birth in teenage mothers.
\end{abstract}

Keywords: Assessment, Patient Health Questionnaire-9, Postpartum depression, Teenage' mothers.

\section{Introduction}

Postpartum depression (PPD) is the common mental disorders after delivery and a considerable becomes a public health problem until one year after-birth [1]. PPD has been called as a hidden illness cause of big difficulties in detecting depression symptoms. Symptoms of PPD may be occasionally awkward to be detected regarding symptoms may be natural in postpartum phenomena. PPD can occur as early as four weeks after childbirth [2],[3]. However, PPD mostly begins within the first one year after-birth [4],[5]. Depression is one of cause of suicide, because prolonged depression that is not treated immediately can cause suicide. At this time, suicide is the second cause of death at the age of 15-29 years [6]. Itis important to early as possible to detect postpartum particularly in teenage mothers

The prevalence of PPD was a ranged from $10 \%$ to $20 \%$ in worldwide [1], [7],[8]. While the estimates of the prevalence of PPD in Indonesia reported to range from $2.5 \%-26.15 \%$ [9],[10]. Judging from the population, postpartum mothers are the second largest contributor to depression after the adolescent population. World Health Organization

[11] released that $16 \%$ adolescent in the world risk for mental health disorder including depression, while about $11,6 \%$ girls in the world getting pregnant. The other condition is in postpartum period a mother had an average three times higher for developing depression than in 
other periods [6]. However, this prevalence varies across studies depending on factors such as the instrument used to measure PPD, time of assessment, cut-off point scores, and population characteristics [12].

Some research in west countries showed that the prevalence of PPD in adolescence mothers was higher than adult mothers. Based on data, the marriage rate for children aged 16 years or less in Indonesia has increased on average from $11.2 \%$ to $20 \%$. The three provinces in Indonesia with the highest youth marriage are South Kalimantan $22.77 \%$, West Java $20.93 \%$ and East Java 20.73\% [13]. Furthermore, research regarding postpartum depression among teenage mothers is limited in Indonesia.

Screening is an effective method used for surveillance and prevention of PPD. There are 2 types of questionnaires for general screening: a self-report and professional report. Self-report assessment is an assessment by a person using a tool designed for examining symptoms of depression according to her perceptions or feelings. A professional report is an assessment by a specialist such as a psychiatrist, obstetrician, or nurse who cares for people with depression for monitoring the symptoms of depression. Postpartum depression screening is important for helping and caring for the patient. Options for screening for PPD often rely on the use of standardized scales or measures. Several tools have been used in the screening and evaluation of postpartum depression. Prior to implementation of the screening protocol, a review of literature conducted the use of standardized scales for the aim of screening or assessment. The instruments for screening PPD include the Edinburgh Postnatal Depression Scale (EPDS), The Postpartum Depression Screening Scale (PDSS), the Beck Depression Inventory (BDI)-II, The Center for Epidemiologic Studies Depression Scale (CESD), The Patient Health Questionnaire (PHQ-9), The Hospital Anxiety and depression Scale (HADS), and The Perinatal Depression Inventory (PDI)-14. In Indonesia most common screening for PPD was using EPDS, and rare using PHQ9. PHQ-9 is a tool to detect postpartum depression symptoms that consist of 9 items. The researcher predict that PHQ-9 can be used to detect postpartum depression in teenage mother in Indonesia population. Our research objective was to asses postpartum depression symptoms in teenage mothers using Patient Health Questionnaire-9 (PHQ-9).

\section{Method}

\section{Design and study settings}

A descriptive design, conducted during July 2020 to August 2020 at Public Health Center in Cianjur and Sukabumi District, West Java Province, Indonesia.

\section{Sample}

An eligible-participants consisted of 203 teenage mothers with age no more than 20 years, postpartum period at one month to one year, who had lived with husband, the baby born weight $\geq 2500$ gram, healthy, and mature, and be able to read, write and speak Bahasa Indonesia. However, subjects who are mentally ill or have a family history of psychiatric problems and baby stillbirth will be excluded. Samples were recruited by consecutive sampling technique.

\section{Instruments}

The instruments used in this study included Patient Health Questionnaire-9 (PHQ-9). Patient Health Questionnaire-9 Indonesia version used to measure postpartum depression symptomatology among teenage mothers. The PHQ-9 was developed as a screener for depression during the development of Primary Care Evaluation of Mental Disorders (PRIME- 
MD) [13]. The PHQ-9 is a self-administered tool based on DSM-IV criteria for diagnosing depressive disorder. The PHQ-9 can be used to monitor severity of depression by the frequency assessing each symptom. The PHQ scale of $0-3$ range of total score is $0-27$.

\section{Data collection}

Institutional Review Board approval from Faculty of Health Sciences, Universitas Islam Negeri Syarif Hidayatullah Jakarta, Indonesia, Number KE.SP/07.08.018/2020. After getting approval, researcher selected randomly the following sites: Public health center in Cianjur District and Sukabumi District West Java, Indonesia, then trained 9 research assistants as an enumerator. Trained one day in data collection in which researcher explained the research objectives, the role of research assistants and the instruments that will be used, provided a manual for data collection.

The researcher or research assistants first met head of public health center to get permission for collected data and ask data of proposed participants. We visited their home guided by cadre of integrated health post. The Assistant researcher asked to selected participants and if they agreed to participated, they filled informed consent. Data collection was conducted at their home. Researcher or assistant researcher asked the participants to complete the questionnaire within 10-15 minutes.

Validity and reliability test was performed in research samples among teenage mothers. Validity test was by using Spearman rho and reliability test was by alpha Cronbach. All items were valid (results more than 0.35 all item) and the result of reliability was 0.78 .

\section{Statistical analyses}

Data analyses were performed with a statistical software program in response to the research objectives. The descriptive statistics was used to describe the studied variables.

\section{Result}

\section{Respondents' Characteristics}

The data from respondents' characteristics showed that more than three-quarter of the participants had graduated from basic education (elementary and intermediate school), almost all $(95.56 \%)$ were house-wives. More than half had family income less than IDR 3 million (equal to \$20), almost all participants was first-time mothers, and almost all had a vaginal delivery (99.01\%). Just over half of the mothers $(59.11 \%$ ) had a baby boy at the current delivery. (Table $1)$.

Table 1. Characteristics of the Respondents

\begin{tabular}{lll}
\hline Variable & $\mathbf{n}$ & $\%$ \\
\hline Level of education Elementary & 67 & 33.00 \\
school & 98 & 48.28 \\
Intermediate school & 38 & 18.72 \\
High school & & \\
Working status House-wives & 194 & \\
& 19 & 95.56 \\
Working & 136 & 6.44 \\
Family Income (IDR) & & 66.99 \\
$\leq 3.000 .000$ & &
\end{tabular}




\begin{tabular}{lll}
$>3.000 .000$ & 67 & 33.01 \\
$\begin{array}{l}\text { Number of Children } \\
\quad \text { One child }\end{array}$ & 188 & 92.61 \\
$\quad$ Two or more children & 15 & 7.39 \\
$\begin{array}{l}\text { Type of deliver } \\
\quad \text { Vaginal birth }\end{array}$ & 201 & \\
$\quad$ Elective C-section & 2 & 99.01 \\
$\begin{array}{l}\text { Current baby's gender } \\
\text { Boy }\end{array}$ & 120 & 0.99 \\
Girl & 83 & 59.11 \\
\hline
\end{tabular}

\section{Symptom of Postpartum Depression}

Symptom of Postpartum Depression was $32.02 \%$. Based on category of postpartum depression by using PHQ-9 exhibited in Table 2.

Table 2. Category of Postpartum Depression using Patient Health Questionnaire-9 ( $\mathrm{N}=203)$

\begin{tabular}{ccc}
\hline Category & $\mathbf{n}$ & $\mathbf{\%}$ \\
\hline No. Depression & 138 & 67.98 \\
Mild depression & 53 & 26.11 \\
Moderate depression & 5 & 2.46 \\
Moderate severe depression & 6 & 2.96 \\
Severe Depression & 1 & 0.49 \\
Total & 203 & 100 \\
\hline
\end{tabular}

From total $32.02 \%$ symptom depression by using PHQ-9, 26.11\% adolescent mothers experienced mild depression and there was 1 mother (0.49) who had experienced severe depression. If we break-down into nine, items of symptom depression exhibited that more than half of the participants were trouble falling or staying asleep, or too much sleep and feeling tired or having little energy; and six participants were thought dead or hurting their selves. (Table 3).

Table 3. Symptom of Postpartum Depression in Patient Health Questionnaire-9 ( $N=203)$

\begin{tabular}{|c|c|c|c|}
\hline No & Item & $\mathbf{n}$ & \% \\
\hline 1. & Little interest or pleasure in doing things & 68 & 33.50 \\
\hline 2. & Feeling down, depressed, or hopeless & 46 & 22.66 \\
\hline 3. & Trouble falling or staying asleep, or sleeping too much & 106 & 52.22 \\
\hline 4. & Feeling tired or having little energy & 114 & 56.16 \\
\hline 5. & Poor appetite/overeating & 76 & 37.44 \\
\hline 6. & $\begin{array}{l}\text { Feeling bad about yourself — or feeling a failure or have let } \\
\text { yourself or your family down }\end{array}$ & 43 & 21.18 \\
\hline 7. & $\begin{array}{l}\text { Trouble concentrating on things, such as reading the } \\
\text { newspaper or watching television }\end{array}$ & 42 & 20.69 \\
\hline 8. & $\begin{array}{l}\text { Moving or speaking so slowly that other people could have } \\
\text { noticed }\end{array}$ & 29 & 14.29 \\
\hline 9. & Thought dead/hurting & 6 & 2.95 \\
\hline
\end{tabular}

\section{Discussion}

The PHQ-9 has been used in a variety of settings. The PHQ-9 has been translated and adapted for diagnosing depressive disorder in several countries including Indonesia. A meta- 
analysis reported that the summary sensitivity of the PHQ-9 was $0.77(0.71-0.84)$ and specificity was $0.94(0.90-0.97)$. The PHQ-2 can be used as a screening tool for depression in primary health care, and patients who screen positive are subject needed to further evaluation [15]. In this research reliability of PHQ-9 was 0.78 . This reliability remains good that means PHQ-9 can be used as tool for self-assessment to detect symptoms of PPD among teenage mothers.

In addition, PHQ-9 was adapted by Hanwela et al [16] in Sri Lanka. Hanwela studied the validity testing that was assessed by correlating total score of PHQ-9 compared to instrument of the Centre for Epidemiological Studies Depression Scale (CESD). The Structured Clinical Interview for DSM-IV conducted by a psychiatrist was the gold standard. The result showed that there was a significant difference in the mean PHQ-9 scores between cases (14.71) and controls $(2.55)(P P<0.001)$ with the specificity was 0.97 ; the sensitivity was 0.58 . Receiver operating characteristic (ROC) analysis found that cut-off score of $\geq 10$ had sensitivity of 0.75 and specificity of 0.97. Furthermore, as comparison standard, the Edinburgh Postpartum Depression Scale (EPDS) Indonesia version is the well-known PPD screening instruments in Indonesia. According to reliability and validity test among 60 postpartum women, EPDS in Indonesian version has sensitivity $92,5 \%$ with prediction value $76,7 \%$ and Alpha coefficient $0,95 \%$ [17].

The research yielded, by using PHQ-9 that $32.02 \%$ teenage mothers had experienced symptom of PPD. If compare to previous study using EPDS, about 35.96\% teenage mothers had experienced symptom of PPD. This finding is higher than similar studies conducted by Nurbaeti et al [10] among adult mothers that reported the prevalence of postpartum depression was $18.37 \%$ in the first month, $15.19 \%$ in the second month and $26.15 \%$ in the third month after-birth. Another research in 2019 in South Jakarta, Indonesia showed a lower rate, about 19.88\% mothers experienced PPD [18]. However, this result is similar with previous study in USA that depression after birth among teenage mother higher fifty percent than adult mother [19]. Although most of mothers experienced mild depression, some of them experienced moderate to severe depression that need further examination and intervention.

From $32.02 \%$ adolescent mothers experienced symptom of postpartum depression, $26.11 \%$ experienced symptom of mild depression, while one mother $(0.49 \%)$ experienced symptom of severe depression. This study is higher than previous study in USA [20] in adult mothers that showed $11.30 \%$ mothers experienced symptom of postpartum depression. It exhibited that teenage mothers tend to have higher risk to get symptom postpartum depression. In line with symptom of depression, more than half mothers felt tired or had little energy and trouble falling or staying asleep or sleeping too much. Even though a small number, there are $2.95 \%$ mothers though dead or hurt their selves. This study is lower than previous study in USA that $6.2 \%$ mothers had suicidal ideation [20].

\section{Conclusion}

The reliability of PHQ-9 remains good to detect symptom of PPD among teenage mothers in Indonesia. We recommend teenage mother to screen for PPD in range from one month to one year after birth, and those who have symptom depression can be evaluated further.

\section{Acknowledgments.}

We would like to thank to Universitas Islam Negeri Syarif Hidayatullah Jakarta, Indonesia on funding supported, and all the mothers who participated in this study. 


\section{References}

[1] O'Hara MW \& McCabe JE. Postpartum depression: current status and future directions. Annual Rev Clin Psychol [Internet].;9:379-407. Available from: http://www.annualreviews.org/doi/abs/10.1146/annurev-clinpsy-050212-185612. (2013)

[2] Beck CT. Predictors of postpartum depression: an update. Nursing Research, 50, 275-285. (2001).

[3] American Psychiatric Association. Diagnostic and statistical manual of mental disorders (5th ed., text revision). Washington, DC: Author.(2013).

[4] Iwata H, Mori E, Sakajo A, Aoki K, Maehara K \& Tamakoshi K. Prevalence of postpartum depressive symptoms during the first 6 months postpartum: Association with maternal age and parity. Journal of Affective Disorders, 203, 227-232. (2016).

[5] Wang L, Wu T, Anderson JL, Florence JE. Prevalence and risk factors of maternal depression during thefirst three years of child rearing. Journal of Women's Health, 20, (5), 711- 718. (2011).

[6] World Health Organization. Maternal Mental Health. (http://www.who.int/mentalhealth/maternalchild/maternal_mental_health/en). Accessed 3 September 2020. (2017).

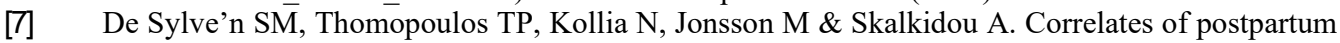
depression in first time mothers without previous psychiatric contact European Psychiatry Volume 40 pp 4-12. (2017).

[8] Werner E, Miller M, Osborne LM, Kuzava S, Monk C. Preventing postpartum depression: review and recommendations. Arch Womens Ment Health.;18(1):41-60. doi:10.1007/s00737-014-0475-y (2015)

[9] Idaiani S \& Basuki B. Postpartum depression in Indonesian women: a national study.Health Science Indonesia; (3), 1, 3-8 (2012)

[10] Nurbaeti I, Deoisres W, Hengudomsub P. Postpartum depression in Indonesian mothers: Its changes andpredicting factors. Pacific Rim Int J Nurs Res.;22(2):93-105. (2018)

[11] World Health Organization. Adolescent Mental _ Health https://www.who.int/news-room/fact-sheets/detail/adolescent-mental-health. Accessed 22 Nopember 2020.

[12] Halbreich U \& Karkum S. Cross-cultural and social diversity of prevalence of postpartum depressionand depressive symptoms. J Affect Disord, 91, 97 - 111.(2006).

[13] Statistics Berau The Republic of Indonesia. Children Marriage in Indonesia 2013 and 2015. Revision Edition. (2018).

[14] Spitzer RL, Kroenke K, Williams JB. Validation and utility of a self-report version of PRIME- MD: the PHQ primary care study. Primary Care Evaluation of Mental Disorders. Patient Health Questionnaire. JAMA. Nov 10;282(18):1737-44. (1999). doi: 10.1001/jama.282.18.1737. PMID: 10568646.

[15] Santos IS, Tavares BF, Munhoz TN, et al. Patient health questionnaire-9 versus Edinburgh postnatal depression scale in screening for major depressive episodes: a cross-sectional population-based study. BMC Res Notes. 9(1):453. (2016). doi:10.1186/s13104-016-2259-0

[16] Hanwella, R, Ekanayake S \& de Silva VA. The Validity and Reliability of the Sinhala Translation of the Patient Health Questionnaire (PHQ-9) and PHQ-2 Screener. Depression Research and Treatment, Article ID 768978, 5 pages. http://dx.doi.org/10.1155/2014/768978.(2014).

[17] Kusumadewi I, Irawati R, Elvira SD \& Wibisono S. Validation study of the Edinburgh postnatal depression scale. Indonesia Psychiatric Quarterly, 31(2), 99-110.(1998).

[18] Nurbaeti I, Deoisres W, Hengudomsub P. Association between psychosocial factors and postpartum depression in South Jakarta, Indonesia. Sexual and Reproductive Healthcare 20 72-76. (2019).

[19] Haroz EE, Ybarra ML \& Eaton WW. Psychometric evaluation of a self-report scale to measure adolescent depression: The CESDR-10 in two national adolescent samples in the United States," Journal. Affective. Disorder., vol. 158, pp. 154-160. (2014). doi: 10.1016/j.jad.2014.02.009.

[20] Yawn BP, Pace W, Wollan PC, Bertram S, et al. "Concordance of Edinburgh Postnatal Depression Scale (EPDS) and Patient Health Questionnaire (PHQ-9) to assess increased risk of depression 
Among postpartum women." Journal of the American Board of Family Medicine : JABFM vol. 22,5

(2009): 483-91. doi:10.3122/jabfm.2009.05.080155 